and Bernardo Bernardi and Ambassador Gasbarri, Secretary-General of the Istituto Italiano per l'Africa. In October 1982, I was able to visit the African Studies Centres in Kyoto, Osaka and Tokyo and had fruitful discussions with Japanese Africanists. As a member of the International Scientific Council of the Republic of Djibouti, which held its inaugural meeting in January 1983, I was able to discuss Institute affairs with the Head of State's Chief of Cabinet and other ministers in Djibouti who are interested in holding one of our seminars there. A visit to Somalia in July provided an opportunity to follow up my approaches to the Somali Government in meetings with ministers and senior officials in several ministries. En route to Somalia I stopped over in Jidda to consult colleagues at King Abdulaziz University about possible future IAI collaboration. Finally, attendance at the Second International Congress of Somali Studies in Hamburg (in early August) provided a welcome opportunity for consulting German and other Africanist colleagues about the Institute's relations and support.

\title{
Conclusions and recommendations
}

The retirement of our Honorary Treasurer and of our Honorary Financial Secretary highlights the urgency of finding appropriate replacements to carry forward and intensify the Institute's search for a more secure financial base. Under Sir Leslie Kirkley's leadership, the Projects and Finance Advisory Panel is playing an important role. But the Institute urgently also requires a Finance Committee led by Finance Officers with the experience and standing which would enable them both to administer the Institute's financial affairs and to take some of the initiatives necessary to secure our future. The problem is to find the right people with sufficient time to devote to the Institute. The Institute is extremely fortunate in having such an energetic Chairman as Professor Jacob Ajayi who frequently visits London and takes every opportunity, through his scholarly contacts, of forwarding the interests of the Institute. As an Honorary Director with heavy responsibilities at the London School of Economics, I have tried to give as much time as possible to Institute affairs. But I feel an outstanding need for further British-based - as well as international - support and am very conscious of how colleagues' numerous other commitments often make it difficult for them to devote as much time and energy as the Institute requires.

So I end this annual review with an appeal for help. The inauguration of our new programme of activities is a promising development. But our hopes for implementing it successfully will depend on our attracting more people with the right qualifications who are prepared to serve the Institute with commitment and dedication. We also desperately need to recoup and expand our membership. All Africanists who share our aims are urged to join (or rejoin) the Institute, subscribing to Africa, and participating in our activities.

\section{SIR GEORGE BERESFORD-STOOKE: A PERSONAL TRIBUTE}

Others have already paid tribute to the political acumen of Sir George Beresford-Stooke, Governor and Commander-in-Chief of Sierra Leone from 1948 to 1953, who died in April 1983. He served as Hon. Treasurer of the Institute from 1955 to 1965 , and as Vice-Chairman from 1957 to 1974 . This is a 
tribute to the qualities of the man from one who served as his Private Secretary and $\mathrm{ADC}$ for the last six months of his time as Governor.

The difference between being an Assistant District Commissioner in various up-country districts and an ADC and Private Secretary at Government House in Freetown was dramatic and entailed, amongst other responsibilities, strict attention to details of protocol. Sir George was known to attach great importance to such matters and it was with some trepidation that I tackled the first seating plan for an official Government House Dinner Party. I took my suggestions to Sir George who told me to draw up a chair so that he could go over the plan with me. He then asked me why I had seated each of the guests in the particular order I had placed them. Such was the kindliness of the man that when he had finished analysing the reasons I gave and told me where I was wrong, I suddenly realized what he had not pointed out, namely, that I had only got three places right - his own and those of Lady Beresford-Stooke and myself. In this and many other ways, he delicately built up my confidence and gained my deep respect. I well remember another occasion when I was speaking about a former member of the Royal West African Frontier Force who was being a thorn in the flesh to some up-country administrators, and was therefore not exactly popular with us. Sir George dwelt on the man's qualities as a leader and said that it would be my duty as an administrator, when I went back to district work, to see how his undoubted energies could best be harnessed. Such advice at the start of a colonial service career constantly stood me in good stead.

Sir George never forgot the importance of developments in the then Protectorate of Sierra Leone. He and Lady Beresford-Stooke were indefatigable in visiting as many places as possible when they went 'on trek' and in meeting all the local dignitaries. On many occasions, part, at least, of the journey was done by train and Sir George loved to survey the countryside from a special 'Governor's' seat which was fastened to the front of the engine. When the time came for Sir George to leave Sierra Leone, he told me to start planning for a large farewell party. At that time, it was the correct form for people to sign the Governor's Book when a new Governor took office or when a Governor was leaving. He asked me to keep his plan secret as he wished invitations to be sent to everyone who had had the courtesy to sign his book in the three weeks preceding the date of the party, that is, all who had signed after the announcement that he would be retiring. Well over 1000 invitations were sent out and it was a remarkable tribute to the affection and esteem in which Sir George and Lady Beresford-Stooke were held, that the vast majority were Sierra Leoneans from ordinary walks of life.

M. J. H. WESTCOTT

\section{DR EVELYN FORDE}

Long-term members of the Institute will be saddened to hear of the death of Dr Evelyn Forde, widow of Daryll Forde, which took place on 4 January. Though not herself an anthropologist, she always maintained a keen interest in her husband's work, accompanying him to Council meetings in Africa and elsewhere. Even after her husband's death, she kept virtually open house in The Boltons for visiting members of Council and other Africanists connected with the Institute. We shall miss her. 